\title{
Study of Improving the Management System of Temporary Resident Population
}

\author{
Yang Yang \\ Southwest University, Chongqing, China \\ Email: yangyangtangxin@vip.qq.com
}

Received September $28^{\text {th }}$, 2013; revised November $1^{\text {st }}, 2013$; accepted November $10^{\text {th }}$, 2013

\begin{abstract}
Copyright (c) 2013 Yang Yang. This is an open access article distributed under the Creative Commons Attribution License, which permits unrestricted use, distribution, and reproduction in any medium, provided the original work is properly cited.
\end{abstract}

\begin{abstract}
Due to the fact that the function for management is abnormally amplified, its service's function is not well reflected when it is carried out for the Management System for Temporary Resident Population. So it will face enormous pressure and there are many problems for the management system for the temporary residential permit and it needs to further be strict and improved. Our government should change from the prevention and control management for the past into the service management which emphasizes on both management and service according to the concept of people-oriented on the basis of retaining and improving the temporary residence registration in current. Firstly, they should further intensify the reform of the household registration system to introduce the concept of citizen treatment and continue to reinforce the value of temporary residential permits. Secondly, the departments will perform their functions and adhere to comprehensively management. Thirdly, they should establish the population management information network to share the resources.
\end{abstract}

Keywords: Temporary Resident Population; the Management System for the Temporary Residence Permit; the Residence Permit

\section{Introduction}

The management system of temporary resident population mainly includes the system for temporary residence registration and the application system of temporary residence permits in China. Now the household registration system is an administrative system, which is established according to the needs of industrialization surpassing strategy. Its establishment reflects the profound contradictions in which China's industrialization process is controlled under the dual structure of urban-rural, and the dual social structure of urban-rural are solidified and increased during the conflict (Wang, 2003). All citizens are divided into two unequal groups for the urban and rural people through adopting the administrative measures. The urban residents can enjoy the welfare benefits and the employment opportunities, while the farmers are bound to the land and strictly limited to move into the urban. After the reform and opening-up, the phenomenon appeared that the large-scale rural population has migrated into the urban continuously while the economic system is changed and the gap between urban and rural has widened. In this case, the temporary registration system for the floating population really began to become a basic and central system to control the population flows (Liu, 2005). Under this background, the interim regulations about the urban transient population' management was formulated by ministry of public security in July, 1985. The application method of temporary residence permits was issued by ministry of public security On June 2, 1995, which provides that the temporary residential permit is a proof for citizens who leave their own' permanent city or township to temporarily stay in other areas. And it provides that citizens should show the ID card or the temporary residential permit when they apply for the service license and the industrial and commercial business license. Its application is associated with the labor rights of people and the management rights. It can be seen that the system for temporary residential permit, since it was born, is not only a form to register for temporary stay for migrant people, but a set of content-rich systems to depend on the urban and rural household registration management.

With the sustained, rapid and healthy development of our socialist market economy, it will be confronted the new challenges and opportunities for public security work. Among them, it is a great importance issue for the management of temporary resident population. There is little information available in the literature about improving the management system of temporary resident population. This will be followed by a description of the fuzzy nature of the problem and a detailed presentation of how to improve it. Recently, all over the country are planning to find a reasonable approach by which the temporary residential permits are replaced by other certificates. The problems have become the focus in the field of academia, media and public for the abolition of temporary residence permits and how to reform for the management system of the temporary resident population. None of the other phases have been examined in detail. We conduct this study to show that the system for temporary residential permit that is mainly charactered with the difference of civil rights will make the floating population feel unfair and lack of the belonging sense, and it will directly influence on the urban's economic development and the urban residents' life. Even if only for the urban's security, it will be 
worse. Thus, this system and its relevant social economic system should be reformed and improved under the condition of reformation for the household registration system and on the basis of remaining and strengthening the management of household registration. It will be beneficial to protecting the civil's legal rights and realizing the social fair service that the management system are further strict and perfected, and it will promote the social's harmony, and progress and the economy's prosperity developments are promoted when balancing the reform, the development and the stability.

\section{The Main Problems in Current}

The practice for temporary residence registration's system, which let population from countryside integrating into the city, is an attempt to adapt to the process of modernization, industrialization and urbanization, and is an epoch-making system design between urban and rural. But we can see that there are still many problems existed in the current management system to transient population.

\section{Discrimination Treatment Still to Exist}

There is no doubt that the residence permit system is a tremendous progress. However, those who hold a residence permit can only enjoy the same service and beneficial policies in some aspects of specifical regulations like the citizen, instead of enjoying the same rights in all aspects. Therefore, it is just better than the temporary residence permit system. The problems are still objectively existed that citizens are enjoyed the unequal rights due to the differences of residence cards and identity. Such as different pay for the same work between urban and rural citizens, different compensation for the same injury and death, the discriminations against outsiders by the locals and so on. It is divided into the permanent residents population and temporary population for the population. The temporary population are differently treated on the policy and institution in field of employment, social security, education and other, and it will let them not enjoying the equal treatments like household population. A great damage will be created for the citizens' equal rights by this difference treatment (Wang, 2001).

\section{The Service Concept of People-Oriented Still to Be Strengthened}

The people have to be divided into the registered permanent residence and the non-registered permanent residence, the permanent household and the temporary household under the facts for the current management system of household registration. The policy-making departments must be subject to the basic values for respecting the human rights and try to be cautious, meticulous and appropriate to make the relevant policy system on the specific details and practices. And they must establish the idea of people-oriented, always to respect people and treat people well, and equally treat for the floating population and the resident population. They can achieve the aim in the follow ways. Firstly, It is necessary to set up the idea to well treat the floating population in the whole society. Secondly, it is necessary to promote them making friends with each other to conspire the urban's development issues. Thirdly, it is necessary to promote them to learn from each other, exchange mutually, get along well and harmony mutually.

\section{The Conflict between the Management System of Temporary Residence Permit with the Administrative Permission Law and the Legislative Law}

It is regulated that any unit and individual have not to rent out apartment or provide the business location for those who fail to obtain the temporary residence permit and that the administration for industry and commerce shall not issue a business license in many local rules, laws and regulations to apply for the temporary residence permits. These regulations belong to the Pre-Setting conditions. But it is stipulated in the article 15th of Administrative Permission Law that the local laws and regulations can not set the administrative permission of which the qualification of citizen, legal person or other organization is uniformly determined by nation, such as and the administrative licensing that should be, and can not set the establishment registration and its pre-administration permission to an enterprise or other organization. It shall not be restricted the individuals or enterprises of other regions to engage in production and business and providing services in here for its administration permission to set. Therefore, it is false that the temporary residence permit of the floating people is as a precondition to rent out apartment, apply for the employment permit and the business license. It is contrary to the provisions of Administrative License Law. The temporary residence permit has become from an administrative confirmation to an administrative permission in its practice. The administrative confirmation is to confirm the relationship of rights and obligations, the legal status and legal facts of the opposing party (Luo, 2001). It is an administrative action to confirm for the registration and application of the temporary residence that the public security organs register for the transient population's situation and give administrative confirmation for their legal facts, rights and obligations and legal status.

\section{Some Suggestions and Measures for It}

\section{Strengthen the Reform for the Household Registration System}

The choice for its abolition must be embedded within the reform process of the household management, as the temporary residence permit is existed to attach to the domicile system. Therefore it will be responsible for transition within the legal framework before the domicile system are thoroughly changed according to law, and it will be weaken its original management's function and transferred to the comprehensive system for social management in the progressive improvement of people-oriented. At the same time, it will be gradually embodied its service efficiency. The government has already started to cancel the different registration for household, weaken the household's influence and the ideas for identity in some regions. It has clearly put forward that the problems of household registration should gradually and conditionally be solved to peasantworkers who work and live in the city for long term in the several opinions about solving the problem of peasant-workers by the State Council. The ministry of public security is now researching the reform's opinions to further deepen the system for household registration. They plan to cancel its boundaries and explore to establish a unified management system for the rural and urban residence registration. While one has a legal domicile as the basic conditions to settle, the restrictions for its migration will be gradually relaxed in the large and medium cites. The 
domicile reform is finally aimed at carrying out to register their residence registration according to the citizen' residence and gradually realizing the freedom of movement according to the market needs and the city' accommodation. It will be formed to the management methods which are organically composed by two kinds of certificates for Household Registration and Identity Card and two kinds of residence registration for temporary and permanent. It will finally be decided to establish a system of laws and regulations for domicile on the basis of Domicile Law and local domicile management's laws and regulations, and establish a management system for domicile that unify the urban and rural to adapt to the social and public management and the market economic development with Chinese Characteristics.

\section{To Increase Its Value by Introducing the Idea of Citizen Treatment}

The residence registrations are undertaken too much functions as a policy of territorial jurisdiction has been adopt in China. It is necessary for the floating population to take temporary registration, otherwise it easily leads residents to separate from household registration, which is not conducive to protect the legal rights and interests of floating population, nor the social management for the inflow lands. It is the premise and foundation for the administrative departments to strengthen the temporary resident population's management as possible as registering and handling their temporary residence permit. The public security bureau will face with a strategic problem how to supervise the floating populations to register their certificate after officially canceling for the measures of detention and and repatriation. It should be incredible thing to face the rolling floating populations if it will carry out to force them registering the certificate. In order to improve their initiative and motivation to register the permit, it is a key to achieve the tangible benefits after registering the certificate. The department can be transformed the temporary resident permit into the service certificate and rights certificate, and can consolidate the temporary residence permit, the marriage certificate, employment permit and other certificates into a new temporary residence permit. Through providing the preferential policies, such as employment, children's education, legal aid, employment training, settling, family planning, purchasing car and house, etc for the floating populations, they will change from the passive registration to the active registration, and a new version of temporary residence permit also will enter into a beneficial cycle for its management services.

\section{To Perform the Departments' Function and Insist on the Comprehensive Management}

We must insist on the work principle of government-dominant, comprehensive management-first, police-oriented, all parties involved. The public security bureaus shall strengthen the management for the registration and certification of temporary resident population according to law, closely control and manage the place of residence and activities for the floating population such as rental housings, construction sites, markets and amusement places, eliminate the potential safety hazards and prevent the crime problems in the center areas inhabited by them. The labor departments should create a new employment mechanism, standardize the labor market and the employment agency, actively provide the services for them such as the employment information, the skills training, the social insurance and so on, and protect their legal rights and interests. The judicial administrative departments should strengthen the law publicity, legal services and dispute mediation for the floating populations. And they initiatively provide the legal aid for the floating populations. The family planning administrative departments should standardize their information's registration, the certificate verification, the technical service by law and improve their service standards of the family planning management to the floating populations. The industrial and commercial administration departments should these carefully implement the system for issuing the business licenses based on his ID card or temporary residence permit and ban the unlicensed business activities. And they should also actively cooperate with the relevant departments to guide the service industry's development of urban community, combine the community service industry and the floating populations' employment to broaden the employment space for the floating population. They also actively safeguard the legal rights and interests for the floating populations engaged in business and industrial work. Other relevant departments, such as city appearance, hygiene, propaganda, the communist youth league, women federations, trade unions, etc, should also need to work according to the division of responsibilities, do it's own work, closely cooperate, and give full play to the comprehensive management. We should coordinate the relationship between the floating populations, urban migrant workers and citizens and make efforts to create the equally harmonious living and development environment for the temporary populations according to the management concept and mode of Civilization, Urban Integration and humanization.

\section{Establishing a Network of Population Information Management to Realize the Sharing Resource}

With the application for the population information management system and its networking construction by public security bureaus, the relevant departments including the ministry of public security have improved their standards for handling the information in the actual management and law enforcement. It makes the temporary residence permit as a functional proof of the administrative management finally disappear and lose its existence necessary by the high efficiency, smooth, safe and practical network information platform. Through establishing and improving the population information management system to the temporary populations, it will be realized that all aspects of information resources, such as population, employment, distribution and social security, etc, are organically integrated and shared. It will provide service for the leadership decisionmaking, management functions and migrant labors' life by strengthening the dynamic monitoring and analysis for the temporary population information. The public security bureaus should regard the construction of state population basic information database as an opportunity based on the Golden Shield Project to strengthen and improve the construction of the public security information management system and promote to share the population information step by step to achieve the interconnection of the social management system and the population information system by public security bureaus (Chen, 2006). It will realize the systematization and informatization for the population information management by the government ser- 
vices platform, the government portal and the relevant departments' database as an external system, if we realize the sharing information between public security, family planning, statistics, civil affairs, social security, tax, education and other departments, based on the public security population fundamental database.

\section{REFERENCES}

Chen, Y. Y. (2006). Study for the situation and suggestion population information management by the public security bureau. Journal of People's Public Security University of China, 4, 56-58.

Liu, J. (2005). Analysis for the temporary residence permit system by the sociology of law. New Angel of Uiew, 9, 57-60.

Luo, H. C. (2001). The administrative law. Beijing: Peking University Press.

Wang, H. L. (2003). Analysis the formation and reformation of current domicile system for China. Journal of Chinese Communist Party History Studies, 4, 33-37.

Wang, X. H. (2001). Study for the legal system of Chinese Domicile. Beijing: People's Public Security University of China Press. 